\title{
Impact of two policy interventions on dietary diversity in Ecuador
}

\author{
Juan Ponce and Jesus Ramos-Martin* \\ Departamento de Desarrollo, Ambiente y Territorio, Facultad Latinoamericana de Ciencias Sociales (FLACSO), \\ La Pradera E7-174 y Av. Diego de Almagro, 170518 Quito, Ecuador
}

Submitted 27 April 2016: Final revision received 3 January 2017: Accepted 10 January 2017: First published online 6 February 2017

\begin{abstract}
Objective: To differentiate the effects of food vouchers and training in health and nutrition on consumption and dietary diversity in Ecuador by using an experimental design.

Design: Interventions involved enrolling three groups of approximately 200 randomly selected households per group in three provinces in Ecuador. Power estimates and sample size were computed using the Optimal Design software, with a power of $80 \%$, at $5 \%$ of significance and with a minimum detectable effect of 0.25 (SD). The first group was assigned to receive a monthly food voucher of $\$$ US 40. The second group was assigned to receive the same $\$$ US 40 voucher, plus training on health and nutrition issues. The third group served as the control. Weekly household values of food consumption were converted into energy intake per person per day. A simple proxy indicator was constructed for dietary diversity, based on the Food Consumption Score. Finally, an econometric model with three specifications was used for analysing the differential effect of the interventions.

Setting: Three provinces in Ecuador, two from the Sierra region (Carchi and Chimborazo) and one from the Coastal region (Santa Elena).

Subjects: Members of 773 households randomly selected ( $n$ 4343).

Results: No significant impact on consumption for any of the interventions was found. However, there was evidence that voucher systems had a positive impact on dietary diversity. No differentiated effects were found for the training intervention. Conclusions: The most cost-effective intervention to improve dietary diversity in Ecuador is the use of vouchers to support family choice in food options.
\end{abstract}

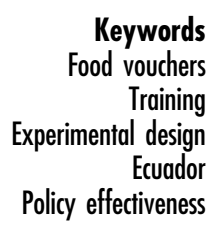

Several developing countries have implemented policies in an attempt to reduce or eliminate malnutrition among children, with a focus on those aged less than 5 years. Among the most frequent policies implemented are cash transfers or conditional cash transfers (CCT), in-kind transfers, mothers' training on health and nutrition issues, infrastructure improvements and vouchers for food $^{(1)}$. In the majority of successful programmes, a combination of interventions is implemented jointly, thus creating uncertainty about exactly which aspect of the policy yielded which result. To the best of our knowledge, few studies have disentangled the separated effect of each component $^{(2)}$. One strategy often used that combines different interventions are CCT programmes. In this kind of programme, cash transfers are generally combined with mothers' training, nutritional supplement, and/or healthcare centre improvements. The research presented herein is the first study to disaggregate the separated effects of each intervention in the Ecuadorian context.

As stated by Torres ${ }^{(3)}$, Ecuador's persistent malnutrition and increasing overweight and obesity are a cause for concern $^{(4-6)}$. According to the National Survey of Health and Nutrition of Ecuador ${ }^{(6)}, 30 \%$ of schoolchildren are estimated to be overweight, while $15 \%$ of them are undernourished. Torres also stressed that health, nutrition and food are scarcely mentioned in the Ministry of Education's curriculum update ${ }^{(7)}$ and quality standards ${ }^{(8)}$. The consequence of this omission is that the main goal of Ecuador's School Feeding Progamme (Programa de

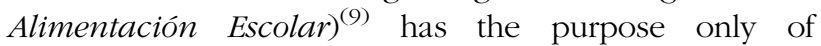
improving student attendance while supplementing children's nutrition. However, this intervention is currently done with a focus on energy intake via fortified cookies and oatmeal, disregarding dietary variety.

The lack of dietary variety is one of the sources of malnutrition in Ecuador. Minimum food diversity, defined as the consumption of at least four food groups during the $24 \mathrm{~h}$ before the survey, was found to be reached by only $63.8 \%$ of breast-fed children between 6 and 23 months old, while this went up to $82.0 \%$ for non-breast-fed children $^{(6)}$. Similar results were found for frequency of food intakes, with $60.0 \%$ of breast-fed and only $37.4 \%$ of 
non-breast-fed children reaching the minimum frequency defined in the survey. Combining the two, dietary variety and frequency of food intakes, results in the so-called minimum acceptable diet, which also shows very low values in Ecuador: $43.4 \%$ for breast-fed children and only $17 \cdot 8 \%$ for non-breast-fed children.

Interventions are designed in many countries to combat malnutrition. Most of the existing literature evaluating interventions such as cash transfers, vouchers and nutrition training are focused on economically deprived populations in developed economies. However, malnutrition is a more pressing issue in Latin America than in developed economies, which explains why CCT programmes are an important component of social policy. Since the initial experiences with CCT in Brazil and Mexico in the second half of the 1990s, most Latin American countries currently run some kind of CCT programme and usually in conjunction with other interventions as a means of reducing poverty and improving human capital. In this regard, CCT programmes provide cash transfers to poor families conditional on the children of these families attending school and/or visiting health-care centres. The attractiveness of these programmes is their potential to combine short- and long-term poverty reduction strategies. The cash transfers reduce short-term poverty, while long-term poverty is curtailed as children of poor families acquire different habits that result in improved human capital. Abundant research is available on the impact of such programmes on human development outcome variables ${ }^{(2)}$. In most of the cases, results show positive effects of CCT programmes on both education and health outcome variables, as well as on reducing poverty and income inequality.

There is a growing number of studies evaluating the impact of such interventions, although they are not conclusive regarding their effectiveness. Yablonski and O'Donnell ${ }^{(10)}$ conducted a survey of case studies worldwide and concluded that, in general, there was evidence that supported the use of cash transfer schemes for improving malnutrition. A few years later, another review ${ }^{(11)}$ analysed twenty experiences in developed economies that included the use of vouchers and other interventions. Only six of the studies were found to have a positive impact when using vouchers for improving dietary variety.

In developed economies, many of the studies have tested only one intervention. In the USA different studies $^{(12-14)}$ have shown how vouchers did increase consumption and improved variety in the diet. In the case of the UK, no conclusive results were found. In some cases changes in consumption or purchasing behaviour were not observed ${ }^{(15)}$, while in other cases both quantity and variety of food were improved by interventions based on vouchers ${ }^{(16,17)}$

There are cases in which more than one intervention was tested, usually including nutritional training or advice and the use of vouchers. Again, the results of the different studies are not conclusive. In one case in the USA ${ }^{(18)}$ both vouchers and education had a positive effect on consumption of fruits and vegetables, but it was the combination of both that resulted in higher impact. In one case in France ${ }^{(19)}$, even though the authors did not differentiate results for each intervention, they concluded that vouchers could be a complementary measure to simply giving advice. In a follow-up of that study ${ }^{(20)}$, however, the authors did measure the differential impact for each intervention and found that vouchers contributed to lowering the risk of low consumption of fruits and vegetables, but they found no difference with the group that received advice only. Finally, in a randomised exercise conducted in New Zealand with 1104 supermarket shoppers, the research showed no relationship between education and healthier purchases, but it did find a relationship between discounts and healthy food purchases $^{(21,22)}$. In general terms, the literature shows in the case of developed economies that vouchers have had an impact on dietary diversity, whereas the impact of nutritional education or training is not that clear.

In the case of developing economies, Gentilini ${ }^{(23)}$ reviewed several studies tackling the issue of cash transfers $v$. in-kind food transfers, leading to the conclusion that although there was relative effectiveness in these interventions, average impacts depended on the context, measurement and programme design.

There is evidence of the positive impact of CCT on nutrition, specifically on stunting, anaemia, weight gain, preventive care visits, chronic malnutrition in infants, dietary diversity and $\mathrm{Hb}$ counts in the Latin American context. In his evaluation of the impact of Mexico's PROGRESA initiative on children's stunted growth and anaemia, Gertler's ${ }^{(24)}$ findings not only revealed no significant impact on children's increased height, but also that the treatment group was $25 \cdot 5 \%$ less likely to be anaemic than the control group. The same data were interpreted by Behrman and Hoddinot ${ }^{(25)}$ who found no positive and, in some cases, even negative impacts on nutritional indicators. A positive impact on nutrition indicators was also found by Maluccio and Flores ${ }^{(26)}$ in their analysis of the Nicaraguan CCT (Red de Protection Social). The same positive impact was found in a case in Honduras ${ }^{(27)}$, in which Siega-Riz et al. reported improvements in micronutrients among participants with respect to the control group. Attanasio et al. ${ }^{(28)}$ evaluated the impact of the Colombian CCT on nutritional indicators. They found a positive and significant impact on chronic malnutrition of about -6.9 percentage points for those aged 24 months or less. One important point of the latter paper is that the authors found a positive impact on dietary diversity. However, there is also evidence of no impact of such interventions. In review of the Honduran PRAF CCT programme, Morris et al. ${ }^{(29)}$ did not find a significant impact on children's nutritional status. The same occurred when evaluating the impact of the Brazilian programme (Bolsa Alimentacion) $^{(30)}$; the authors found no evidence 
of weight difference between children belonging to programmes and those excluded from them at the time of enrolment. Paxson and Schady ${ }^{(31)}$ evaluated the impact of the Ecuadorian CCT programme (Bono de Desarrollo Humano) on nutritional indicators among children between 3 and 7 years old. Their study showed no significant effects on children's malnutrition rates.

One limitation of most of the studies presented above is that the effects of the different components of the programmes are not easily identified and very often not even measured. One exception is the paper by Hidrobo et $a l .{ }^{(32)}$. These authors considered the comparative costs and nutritional outcomes of offering participants cash, food vouchers or food transfers. All three modalities were found to significantly improve the quantity and quality of food consumed. However, the study did not analyse nutritional and health training. Hidrobo et al.'s analysis showed that offering food transfers was the least cost-effective method while food vouchers were the most cost-effective.

Building on the variety of studies presented above, our hypothesis is that food vouchers have a differentiated impact when compared with training in terms of costeffectiveness. The rationale behind the hypothesis is that malnutrition is often, although not only, determined by budgetary constraints of households, which prevent them from having access to a diversified diet, which in turn drives nutritional problems in children such as those described above for Ecuador.

This is thus the contribution of the present paper, as we differentiate the effects of two components of a nutritional programme by using an experimental design. In our study, we randomly assigned households to one of the following three groups: (i) food voucher; (ii) voucher plus training in health and nutrition; and compared them with (iii) a control group which received none of the above. This design permitted us to differentiate the effects of each component of the different interventions.

\section{Methods}

\section{Experimental design and interventions}

Three groups of approximately 200 households per group were randomly selected in three provinces in Ecuador, two from the Sierra region (Carchi and Chimborazo) and one from the Coastal region (Santa Elena). Power estimates as well as sample size were computed using the Optimal Design software, working with a power of $80 \%$, at $5 \%$ significance and with a minimum detectable effect of $0 \cdot 25$ (sD). The baseline survey was conducted between September and November 2013 prior to a follow-up survey for each of the three groups one year later.

The first group of households (T1) was assigned to receive a monthly food voucher of $\$$ US 40 . The second group of households (T2) was assigned to receive the same \$US 40 voucher, plus training on health and nutrition issues.* Finally, the third group (C) served as the control and did not receive intervention. Analysis of the three groups yielded the following impacts:

$\mathrm{T} 1-\mathrm{C}=$ the impact of the food voucher;

$\mathrm{T} 2-\mathrm{C}=$ the impact of the food voucher and training; and

$\mathrm{T} 2-\mathrm{T} 1(\mathrm{~T} 3)=$ the impact of training.

Two different outcome variables were analysed for each of the three groups: (i) per capita energy consumption at household level; and (ii) dietary diversity. Each of these variables is described below.

\section{Per capita energy consumption at household level}

Following Hidrobo et al. ${ }^{(32)}$, household food consumption aggregates were constructed from the amounts of foods eaten at home and outside the home over a $7 \mathrm{~d}$ period. Weekly household values of food consumption were then converted to monthly values, which were subsequently converted to household per capita values by dividing the total by the number of household members. Results are robust to using adult equivalent values. Energy intake was constructed from the amounts of foods consumed at home (from purchases, own stock or in-kind payments). The amount of food consumed for each item was multiplied by its energy content to obtain kilocalories consumed ${ }^{(33)}$. Total weekly household energy values were then converted to daily amounts and divided by household size to obtain energy intake per person per day. The median energy intake for forty distinct food items was used to determine the per capita energy consumption.

\section{Dietary diversity}

The present study used the Food Consumption Score $(\text { FCS })^{(34)}$, which considers the number of days that the household consumed the corresponding food group (staples, pulses, vegetables, fruit, meat and fish, milk and dairy, sugar and honey, oils and fats), multiplied by the number of days of the food group's weighted frequencies. The sum of the total categories was obtained to create a simple proxy indicator.

\section{Model specification}

Taking advantage of the panel data, the treatment effect was estimated using the following econometric specification:

$$
Y_{i 1}=\alpha+X_{i 0}^{\prime} \beta_{0}+\beta_{1} T_{i}+\beta_{2} Y_{i 0}+\varepsilon_{i},
$$

where $Y_{i 1}$ is the outcome of interest for child $i$ at follow-up; the sub-index 1 is for the follow-up and 0 for the baseline; $T_{i}$ are indicators that equal 1 if the household is in the corresponding treatment arm and 0 otherwise; $\beta_{1}$ is the

\footnotetext{
* Monthly training sessions included topics on nutrition (and malnutrition), food preparation, children's health, mother's health, women's rights and women's empowerment.
} 
corresponding impact estimate; $X^{\prime}$ is a vector of control variables at baseline; and $Y_{i 0}$ is the outcome of interest at baseline.

Three specifications were reported. First, the basic specification only included dummies for the corresponding treatment. For each type of intervention several treatments were used, as well as dummies for comparing different interventions. T1 and T2 stand for each different type of intervention. T3 (T2-T1) takes the value of 1 for voucher plus training and 0 for voucher. Finally, T0 takes the value of 1 for all of the treatment groups and 0 for the control group.

The second specification included, as a control variable, the value of the outcome variable at baseline. The third specification included the basic specification plus control variables at the household and head of household level. The age of the household head and number of years of schooling, and dummies for being female and indigenous were included at this level. Finally, the number of children by age grouping ( $0-5$ years old, 6-14 years old) and the number of other household members by age grouping (15-44 years old, 45-65 years old and older than 65 years) were also considered.

The differences between random assignment and the real treatment impelled the use of an instrumental variable estimation, where treatment was instrumented by the original random assignment. As is accepted in the field, the study presumed that the original random assignment is a good instrument if two conditions were met: (i) if the instrument is a good predictor of the real treatment; and (ii) if the instrument meets the 'exclusion restriction', which means that the only way of affecting the outcome variable is through programme participation.

Regarding the first condition, Table 1 introduces the results of the regression between the instrument and the real treatment. In all cases the coefficient was highly significant and with values larger than $0 \cdot 9$. The $F$ value for the instrument was significant in all cases.

By using random assignment as the primary instrument, our estimates represent the local average treatment effect. This means that it represents the impact on those people

Table 1 Ordinary least-squares regression results between the treatment arms and random assignment in the experimental design differentiating the effects of food vouchers and training in health and nutrition on consumption and dietary diversity among approximately 200 randomly selected households per group in three provinces in Ecuador

\begin{tabular}{lcccc}
\hline & T1 & T2 & T3 & T0 \\
\hline Coefficient & 0.9766 & 0.155 & 0.8727 & 0.9141 \\
SE & 0.0109 & 0.0158 & 0.0183 & 0.0140 \\
$F$ value for the & 7930.19 & 3352.90 & 2262.40 & 4243.66 \\
$\quad$ instrument & & & & \\
Number of cases & 362 & 576 & 558 & 773 \\
\hline
\end{tabular}

T1 = monthly food voucher of \$US $40 ; \mathrm{T} 2=$ the same \$US 40 voucher plus training on health and nutrition issues; T3 $=\mathrm{T} 2-\mathrm{T} 1$ ( = the impact of training); $\mathrm{TO}=1$ for all of the treatment groups and 0 for the control group. who received the intervention because they were randomly assigned to participate in the programme.

\section{Data and baseline characteristics}

Table 2 introduces the results for the baseline survey. Results from baseline showed no systematic differences between each treatment arm and the control group, or among the different treatment arms. More specifically, no differences were found between $\mathrm{T} 1$ and $\mathrm{C}$, between $\mathrm{T} 2$ and $\mathrm{C}$, or between $\mathrm{T} 1$ and $\mathrm{T} 2$. We found only a significant difference between T1 and T2 in the number of members aged 45-64 years old at household level. The lack of significant differences indicates that the randomisation worked properly. However, to get more precise estimations and to correct for possible differences in baseline, all variables included in Table 1 were incorporated as control variables in the more complete specification used in the econometric models.

\section{Results}

To analyse results, the impact on per capita consumption and total household consumption (in logs) was evaluated (Table 3). No significant impacts were found when using the log of per capita consumption in energy terms as the dependent variable. However, when the log of total consumption at household level in energy terms was considered, the dependent variable had a significant impact on household consumption of T2 (voucher plus training). There were no other significant impacts found for the rest of the treatment arms.

Table 4 reports the results for dietary diversity. The diversity dietary index takes values between 1 and 8 with larger values indicating more dietary diversity. Results showed a significant and positive impact of all interventions on dietary diversity. The impact of T1 and T2 were 0.4 and $0 \cdot 3$, respectively. However, there was no difference in impact across the different intervention arms. This important finding means that the voucher represents the most cost-effective intervention in relation to dietary diversity.

\section{Discussion and conclusions}

Policy measures oriented to reduce malnutrition in children are present in most developing countries, especially in Latin America. They are usually expensive programmes that include different sorts of interventions, including cash transfers, food vouchers and nutritional education or training. However, in many cases the differentiated outcomes of each intervention are not measured, leading to poor results regardless of the amount of money invested. In this regard, the main implication of our findings is that these countries, where budgetary constraints are more important than in developed countries, should focus their interventions on providing conditional food vouchers to 
Table 2 Baseline variables in the treatment arms and control group in the experimental design differentiating the effects of food vouchers and training in health and nutrition on consumption and dietary diversity among approximately 200 randomly selected households per group in three provinces in Ecuador

\begin{tabular}{|c|c|c|c|c|c|c|}
\hline \multirow[b]{2}{*}{ Variable } & \multicolumn{3}{|c|}{ Mean } & \multicolumn{3}{|c|}{$P$ value for difference } \\
\hline & C & T1 & $\mathrm{T} 2$ & $\mathrm{~T} 1-\mathrm{C}$ & $\mathrm{T} 2-\mathrm{C}$ & $\mathrm{T} 1-\mathrm{T} 2$ \\
\hline \multicolumn{7}{|l|}{ Household head characteristics } \\
\hline Years of schooling & $7 \cdot 535$ & $7 \cdot 731$ & 7.638 & 0.579 & 0.729 & 0.760 \\
\hline Female & 0.170 & 0.170 & 0.175 & 0.992 & 0.889 & 0.885 \\
\hline Age (years) & 33.8 & $32 \cdot 6$ & $34 \cdot 0$ & 0.370 & 0.857 & 0.226 \\
\hline Mestizo & 0.795 & 0.766 & 0.810 & 0.504 & 0.656 & 0.242 \\
\hline \multicolumn{7}{|l|}{ Household characteristics } \\
\hline Number of children aged $0-5$ years & 1.527 & 1.480 & 1.564 & 0.494 & 0.548 & 0.169 \\
\hline Number of members aged $6-14$ years & 0.821 & 0.836 & 0.736 & 0.894 & 0.338 & 0.330 \\
\hline Number of members aged $15-44$ years & $2 \cdot 149$ & 2.333 & $2 \cdot 239$ & 0.100 & 0.291 & 0.363 \\
\hline Number of members aged $45-65$ years & 0.259 & 0.181 & 0.314 & 0.174 & 0.298 & 0.008 \\
\hline Number of members aged $>65$ years & 0.264 & 0.292 & 0.204 & 0.663 & 0.304 & 0.128 \\
\hline \multicolumn{7}{|l|}{ Outcome variable } \\
\hline Household energy intake $(\mathrm{kcal} / \mathrm{d}) \dagger$ & 7638.6 & 7529.6 & $7415 \cdot 6$ & 0.807 & 0.544 & 0.769 \\
\hline Per capita energy intake $(\mathrm{kcal} / \mathrm{d}) \dagger$ & $1660 \cdot 8$ & $1635 \cdot 6$ & $1609 \cdot 6$ & 0.817 & 0.532 & 0.786 \\
\hline Dietary diversity index & 5.89 & 5.96 & $5 \cdot 83$ & 0.595 & 0.630 & 0.281 \\
\hline Number of individuals & 997 & 920 & 2426 & & & \\
\hline Number of cases (households) & 201 & 171 & 401 & & & \\
\hline
\end{tabular}

$\mathrm{C}=$ control, no intervention; T1 = monthly food voucher of $\$ U S 40 ; \mathrm{T} 2=$ the same $\$ \mathrm{US} 40$ voucher plus training on health and nutrition issues.

†To convert to $\mathrm{kJ} / \mathrm{d}$, multiply $\mathrm{kcal} / \mathrm{d}$ value by $4 \cdot 184$.

Table 3 Impact of treatments on energy consumption (logs; two-stage least-squares estimates) in the experimental design differentiating the effects of food vouchers and training in health and nutrition on consumption and dietary diversity among approximately 200 randomly selected households per group in three provinces in Ecuador

\begin{tabular}{|c|c|c|c|c|c|c|}
\hline & \multicolumn{3}{|c|}{ Per capita } & \multicolumn{3}{|c|}{ Household } \\
\hline & Specification 1 & Specification 2 & Specification 3 & Specification 1 & Specification 2 & Specification 3 \\
\hline \multicolumn{7}{|l|}{ T1 } \\
\hline Coefficient & -0.007 & 0.009 & 0.014 & 0.037 & 0.034 & 0.045 \\
\hline SE & 0.074 & 0.068 & 0.068 & 0.072 & 0.068 & 0.066 \\
\hline Number of cases & 336 & 336 & 336 & 336 & 336 & 336 \\
\hline \multicolumn{7}{|l|}{ T2 } \\
\hline Coefficient & 0.056 & 0.079 & 0.081 & $0 \cdot 101^{(\star)}$ & $0.106^{(\star)}$ & $0.090^{(*)}$ \\
\hline SE & 0.064 & 0.059 & 0.059 & 0.063 & 0.059 & 0.058 \\
\hline Number of cases & 512 & 512 & 512 & 512 & 512 & 512 \\
\hline \multicolumn{7}{|l|}{ T3 } \\
\hline Coefficient & 0.070 & 0.084 & 0.082 & 0.059 & 0.076 & 0.047 \\
\hline SE & 0.067 & 0.063 & 0.063 & 0.066 & 0.063 & 0.061 \\
\hline Number of cases & 513 & 513 & 513 & 513 & 513 & 513 \\
\hline \multicolumn{7}{|l|}{ TO } \\
\hline Coefficient & 0.029 & 0.046 & 0.049 & 0.075 & 0.074 & 0.065 \\
\hline SE & 0.060 & 0.056 & 0.056 & 0.059 & 0.056 & 0.055 \\
\hline Number of cases & 697 & 697 & 697 & 697 & 697 & 697 \\
\hline
\end{tabular}

$\mathrm{T} 1=$ monthly food voucher of $\$ \mathrm{US} 40 ; \mathrm{T} 2=$ the same $\$ \mathrm{US} 40$ voucher plus training on health and nutrition issues; $\mathrm{T} 3=\mathrm{T} 2-\mathrm{T} 1$ (= the impact of training); T0 =1 for all of the treatment groups and 0 for the control group.

Specification 1 includes dummies for the corresponding treatment. Specification 2 includes, as a control variable, the value of the outcome variable at baseline. Specification 3 includes Specification 2 plus control variables at the household and head of household level.

${ }^{(*)}$ Significant at the $10 \%$ level.

households. Such vouchers have a positive impact on dietary diversity at a lower cost than vouchers plus training. This does not mean education is not important, as we discuss below.

In terms of public policy, our findings suggest at least two areas of work. The first is to study how to integrate and expand the voucher programmes to the entire population in order to have a significant impact. One way to easily implement this would be by modifying the current Ecuadorian CCT - the Human Development
Bond ${ }^{(35)}$ - which is a subsidy for low-income households by attaching it to certain obligations. In 2013, about 1 million households benefited from these at \$US 35 per month. The bond could be converted into food vouchers, tradable for certain food items that would guarantee dietary diversity within the 1 million households that are current beneficiaries. This would reverse some of the nutritional problems found in Ecuador and discussed in the present paper's introduction. This change would be consistent with previous research that showed the need 
Table 4 Impact of treatments on dietary diversity (two-stage leastsquares estimates) in the experimental design differentiating the effects of food vouchers and training in health and nutrition on consumption and dietary diversity among approximately 200 randomly selected households per group in three provinces in Ecuador

\begin{tabular}{|c|c|c|c|}
\hline & $\begin{array}{c}\text { Specification } \\
1 \\
\end{array}$ & $\begin{array}{c}\text { Specification } \\
2 \\
\end{array}$ & $\begin{array}{c}\text { Specification } \\
3 \\
\end{array}$ \\
\hline \multicolumn{4}{|l|}{ T1 } \\
\hline Coefficient & $0.424^{* *}$ & $0.396^{* *}$ & $0.394^{\star *}$ \\
\hline SE & 0.052 & 0.050 & 0.050 \\
\hline Number of cases & 1834 & 1834 & 1834 \\
\hline \multicolumn{4}{|l|}{ T2 } \\
\hline Coefficient & $0.357^{\star *}$ & $0.330^{\star *}$ & $0 \cdot 291^{* *}$ \\
\hline SE & 0.083 & 0.082 & 0.081 \\
\hline $\begin{array}{l}\text { Number of cases } \\
T 3\end{array}$ & 2878 & 2878 & 2878 \\
\hline \multicolumn{4}{|l|}{ T3 } \\
\hline $\begin{array}{l}\text { Coefficient } \\
\text { SE }\end{array}$ & $\begin{array}{r}-0.092 \\
0.078\end{array}$ & $\begin{array}{r}-0.088 \\
0.077\end{array}$ & $\begin{array}{r}-0.125 \\
0.077\end{array}$ \\
\hline Number of cases & 2825 & 2825 & 2825 \\
\hline \multicolumn{4}{|l|}{ TO } \\
\hline Coefficient & $0.395^{\star \star}$ & $0.358^{* *}$ & $0.333^{\star \star}$ \\
\hline SE & 0.075 & 0.073 & 0.073 \\
\hline Number of cases & 3910 & 3910 & 3910 \\
\hline
\end{tabular}

$\mathrm{T} 1=$ monthly food voucher of $\$$ US $40 ; \mathrm{T} 2=$ the same $\$$ US 40 voucher plus training on health and nutrition issues; $\mathrm{T} 3=\mathrm{T} 2-\mathrm{T} 1$ ( $=$ the impact of training); T0 $=1$ for all of the treatment groups and 0 for the control group. Specification 1 includes dummies for the corresponding treatment. Specification 2 includes, as a control variable, the value of the outcome variable at baseline. Specification 3 includes Specification 2 plus control variables at the household and head of household level.

${ }^{* *}$ Significant at the $1 \%$ level.

for modifying the design of the bond as it had modest impacts on children's nutritional status in Ecuador ${ }^{(31,36)}$.

The second is to analyse why training programmes have such a low impact on dietary diversity in Ecuador and elsewhere, as shown in the present study and the studies highlighted. Torres ${ }^{(3)}$ notes that there is a great potential for food and nutrition education at schools, if a holistic perspective is applied that considers food's social, economic, cultural, historical, environmental and even emotional and sensory connections. This could be enlarged to include education on production systems and procurement, with links to their impact upon labour conditions and the environment. According to Torres, such an initiative would easily fit with the Ecuadorian Development Plan, called the National Plan for Good Living ${ }^{(37)}$, and with its key concept of good living. In this way, the School Feeding Programme described above should not be restricted to improving student's attendance and providing nutritional supplements, but rather engage in also providing nutritional education to children, probably by including these topics in the curriculum. This would guarantee further impact of training programmes once parents are included. Last, these measures would be even more effective if the country had, as in many other countries, a national institute of research on food and nutrition, which is currently missing.

Although the literature covered herein on interventions to reduce malnutrition have focused mainly on cash transfers and vouchers, most of the studies that also covered nutritional education and training reached the same conclusion as the present study: training has moderate or no effect in improving dietary diversity ${ }^{(20-22)}$. Only in certain developed countries does training have a moderate impact ${ }^{(18,19)}$. With regard to cash transfers and food vouchers, some studies showed no impact, as in the case of Honduras ${ }^{(29)}$, Brazil $^{(30)}$ and Ecuador ${ }^{(31)}$, while most of the cases showed positive impacts. This is the case in both developed ${ }^{(10-14,16-18,20)}$ and developing economies $^{(26-28)}$. Our study contributes further in that its findings show food vouchers have a positive impact on dietary diversity.

The major strength of our study is the differentiation of the relative impact of each intervention, which, as we saw above, is usually not present in the literature. Regarding limitations, our study analyses the impact on dietary diversity only, and therefore the nutritional status of children is not covered. Although we had collected evidence on this issue, the size of the sample was not big enough to offer conclusive results and for that reason we decided not to include it here.

Future research in Ecuador could fill knowledge gaps in at least two different ways. On the one hand, it could include an evaluation of interventions on nutritional status of children, requiring bigger sample sizes than the one used here. On the other hand, it could focus on designing changes to the current CCT programme (the Human Development Bond), so that food vouchers are used instead of cash transfers, in a more cost-effective way.

In conclusion, after evaluating the separated impact of food voucher programmes and vouchers plus training on consumption and dietary diversity in different regions of Ecuador, the following main results were found:

1. Dietary diversity alone was found to be influenced by the food voucher programme, as well as the training.

2. The study did not find any significant impact of the interventions on consumption.

3. Surprisingly, the training showed similar magnitude of impacts with no significant differences with respect to the food voucher programme on dietary diversity.

4. The nutritional status of children should also be evaluated in future analyses of these types of intervention.

5. Ecuador could dramatically increase the impact of current CCT programmes if food vouchers were distributed instead of cash transfers, being a more cost-effective measure, as it would increase dietary diversity for more than 1 million households at no extra cost with respect to the budget of the current programme.

6. Based on these results, we conclude that the most costeffective intervention in the case of Ecuador is the voucher programme.

\section{Acknowledgements}

Acknowledgements: The authors would like to thank the associate editor and three anonymous reviewers for their 
comments that have greatly improved the work presented here. Financial support: This work was supported by the World Food Programme in Ecuador and by the Spanish Ministry of Science and Innovation (grant number HAR2013-47182-C2-1-P). The funders had no role in the design, analysis or writing of this article. Conflict of interest: None. Authorship: J.P. formulated the research question, designed the study, carried it out, analysed the data and wrote the article. J.R.-M. drafted the article, revised it critically and edited it. Ethics of buman subject participation: This study was conducted according to the guidelines laid down in the Declaration of Helsinki and all procedures involving human subjects/ patients were approved by the FLACSO Ethics Committee. Written informed consent was obtained from all subjects/ patients.

\section{References}

1. van den Bold M, Quisumbing AR \& Gillespie S (2013) Women's Empowerment and Nutrition. An Evidence Review. IFPRI Discussion Paper no. 01294. Washington, DC: International Food Policy Research Institute.

2. Fiszbein A \& Schady N (2009) Conditional Cash Transfers. Reducing Present and Future Poverty. Washington, DC: The World Bank.

3. Torres I (2016) Policy windows for school-based health education about nutrition in Ecuador. Health Promot Int (Epublication ahead of print version).

4. Freire WB, Silva-Jaramillo KM, Ramirez-Luzuriaga MJ et al. (2014) The double burden of undernutrition and excess body weight in Ecuador. Am J Clin Nutr 100, issue 6, 1636S-1643S.

5. Popkin BM, Adair LS \& Ng SW (2012) Global nutrition transition and the pandemic of obesity in developing countries. Nutr Rev 70, 3-21.

6. Freire WB, Ramírez MJ, Belmont P et al. (2014) Tomo I: Encuesta Nacional de Salud y Nutrición de la población ecuatoriana de cero a 59 años. ENSANUT-ECU 2012. Quito: Ministerio de Salud Pública.

7. Ecuadorian Ministry of Education (2010) Actualización y Fortalecimiento Curricular de la Educación General Básica (Curriculum Update and Strengthening for Basic Education). Quito: Ministry of Education.

8. Ecuadorian Ministry of Education (2012) Estándares de Calidad Educativa (Education Quality Standards). Quito: Ministry of Education.

9. Ecuadorian Ministry of Education (2012) Proyecto Programa de Alimentación Escolar (School Feeding Program). Quito: Ministry of Education.

10. Yablonski J \& O'Donnell M (2009) Lasting Benefits. The Role of Cash Transfers in Tackling Child Mortality. London: Save the Children.

11. An R (2013) Effectiveness of subsidies in promoting healthy food purchases and consumption: a review of field experiments. Public Health Nutr 16, 1215-1228.

12. Dimitri C, Oberholtzer L, Zive M et al. (2015) Enhancing food security of low-income consumers: an investigation of financial incentives for use at farmers' markets. Food Policy 52, 64-70.

13. Herman DR, Harrison GG \& Jenks E (2006) Choices made by low-income women provided with an economic supplement for fresh fruit and vegetable purchase. $J \mathrm{Am}$ Diet Assoc 106, 740-744.
14. Herman DR, Harrison GG, Afifi AA et al. (2008) Effect of a targeted subsidy on intake of fruits and vegetables among low-income women in the Special Supplemental Nutrition Program for Women, Infants, and Children. Am J Public Health 98, 98-105.

15. Buyuktuncer Z, Kearney M, Ryan CL et al. (2014) Fruit and vegetables on prescription: a brief intervention in primary care. J Hum Nutr Diet 27, 186-193.

16. Burr ML, Trembeth J, Jones KB et al. (2007) The effects of dietary advice and vouchers on the intake of fruit and fruit juice by pregnant women in a deprived area: a controlled trial. Public Health Nutr 10, 559-565.

17. McFadden A, Green JM, Williams V et al. (2014) Can food vouchers improve nutrition and reduce health inequalities in low-income mothers and young children: a multi-method evaluation of the experiences of beneficiaries and practitioners of the Healthy Start programme in England. BMC Public Health 14, 148.

18. Anderson JV, Bybee DI, Brown RM et al. (2001) 5 a day fruit and vegetable intervention improves consumption in a low income population. J Am Diet Assoc 101, 195-202.

19. Bihan H, Castetbon K, Mejean C et al. (2010) Sociodemographic factors and attitudes toward food affordability and health are associated with fruit and vegetable consumption in a low-income French population. J Nutr 140, 823-830.

20. Bihan H, Méjean C, Castetbon K et al. (2012) Impact of fruit and vegetable vouchers and dietary advice on fruit and vegetable intake in a low-income population. Eur J Clin Nutr 66, 369-375.

21. Blakely T, Ni Mhurchu C, Jiang Y et al. (2011) Do effects of price discounts and nutrition education on food purchases vary by ethnicity, income and education? Results from a randomised, controlled trial. J Epidemiol Community Health 65, 902-908.

22. Ni Mhurchu C, Blakely T, Jiang Y et al. (2010) Effects of price discounts and tailored nutrition education on supermarket purchases: a randomized controlled trial. Am J Clin Nutr 91, 736-747.

23. Gentilini U (2015) Revisiting the 'cash versus food' debate: new evidence for an old puzzle? World Bank Res Obs 31, $135-167$.

24. Gertler P (2004) Do conditional cash transfers improve child health? Evidence from PROGRESA's control randomized experiment. Am Econ Rev 94, 336-341.

25. Behrman JR \& Hoddinott J (2005) Programme evaluation with unobserved heterogeneity and selective implementation: the Mexican PROGRESA impact on child nutrition. Oxf Bull Econ Stat 67, 547-569.

26. Maluccio JA \& Flores R (2005) Impact Evaluation of a Conditional Cash Transfer Program: The Nicaraguan Red de Protección Social. FNCD Discussion Paper no. 184. Washington, DC: International Food Policy Research Institute.

27. Siega-Riz AM, Estrada Del Campo Y, Kinlaw A et al. (2014) Effect of supplementation with a lipid-based nutrient supplement on the micronutrient status of children aged 6-18 months living in the rural region of Intibucá, Honduras. Paediatr Perinat Epidemiol 28, 245-254.

28. Attanasio O, Gómez LC, Heredia P et al. (2005) The Shortterm Impact of a Conditional Cash Subsidy on Child Health and Nutrition in Colombia. Report Summary: Familias 03. London: Institute for Fiscal Studies.

29 Morris SS, Flores R, Olinto P et al. (2004) Monetary incentives in primary health care and effects on use and coverage of preventive health care interventions in rural Honduras: cluster randomised trial. Lancet 364, 2030-2037. 
30. Morris SS, Olinto P, Flores R et al. (2004) Conditional cash transfers are associated with a small reduction in the rate of weight gain of preschool children in northeast Brazil. J Nutr 134, 2336-2341.

31. Paxson C \& Schady N (2010) Does money matter? The effects of cash transfers on child development in rural Ecuador. Econ Dev Cult Change 59, 187-229.

32. Hidrobo M, Hoddinott J, Peterman A et al. (2014) Cash, food, or vouchers? Evidence from a randomized experiment in northern Ecuador. J Dev Econ 107, 144-156.

33. Ministerio de Salud Pública del Ecuador (2010) Tabla Compilada de Composición Química de Alimentos
Ecuatorianos, revisión de 2010. Quito: Ministerio de Salud Pública.

34. World Food Programme (2008) Food Consumption Analysis. Calculation and Use of the Food Consumption Score in Food Security Analysis. Rome: World Food Programme.

35. Ministerio de Inclusión Económica y Social (2013) Informe de Gestión. Quito: Ministerio de Inclusión Económica y Social.

36. León M \& Younger SD (2007) Transfer payments, mothers' income and child health in Ecuador. J Dev Stud $\mathbf{4 3}$, 1126-1143.

37. National Secretariat of Planning and Development (2013) National Plan for Good Living 2013-2017. Quito: SENPLADES. 